\title{
Kurum Kültürünün Devam Ettirilmesinde Sürdürülebilir Liderlik
}

\author{
DOI: 10.26466/opus.910771
}

\author{
* \\ Münevver Çetin * - Şeyda Bas** \\ * Prof. Dr., Marmara Üniversitesi, Eğitim Bilimleri, İstanbul/Türkiye \\ E-Posta: munevverolcum@gmail.com \\ ORCID: $\underline{0000-0002-1203-9098}$ \\ ** Doktora Öğrencisi, Marmara Üniversitesi, Eğitim Bilimleri, İstanbul/Türkiye \\ E-Posta: bas.seyda@gmail.com ORCID: $\underline{\text { 0000-0003-1218-6327 }}$
}

Öz

Geçmişte rolleri bürokratik kuralları uygulamakla sinırlı olan okul müdürleri, 21. yüzyılda farklı roller üstlenmek zorunda kalmaktadır. Bu rollerden biri, okullarda yeniliklere öncülük etmeleri ve yeniliklerin sürdürülebilir ve etkili olmasını sağlamaktır. Değişen yüzyılın şartlarına uygun olarak, okul yöneticilerinin okulları yenilikçi profesyonel öğrenme topluluklarına dönüştürülmelerini sağlayacak sürdürülebilir liderlik tarzın üstlenmeleri faydalı olabilir. Sürdürülebilir liderlik anlayışı, okulda reformist, yenilikçi ve öğrenme odaklı kurum kültürünün kalıcı olmasını să̆layabilir. Mevcut çalışmada, kurum kültürünün devam ettirilmesinde sürdürülebilir liderliğin önemine ilişkin öğretmen görüşlerine ulaşılması amaçlanmıştır. Araştırmada nitel araştırma yöntemlerinden örnek olay çalışması kullanılmıştır. Çalışma grubu olarak, kurumlarında en az 1 yıldır görev yapan 15 öğretmene ulaşılmıştır. Literatür ayrıntılı bir şekilde taranarak araştırmacılar tarafindan örnek olay oluşturulmuştur. Kod, kategori ve temaların oluşturulması için içerik analizi kullanılmıştır. Araştırma sonucunda, öğretmenlerin sürdürülebilir kurum kültürüne karşı olumlu tutuma sahip oldukları, en çok yönetsel sürdürülebilir liderlik davranışlarna önem verdikleri ve kurum kültürünün devam ettirilmesinin tek bir kişiye bağhl olduğunu ifade ettikleri görülmektedir. Katılımo öğretmenlerin ifadelerinden, okul müdürleri tarafindan sürdürülebilir liderlik davranışlarının sınırlı düzeyde sergilendiği anlaşılmaktadır. Sürdürülebilir liderliğin eğitim kurumlarına olan etkilerinin somut ve uzun süreli olup olmadığının değerlendirilmesi için boylamsal araştırmaların yapılması faydalı olabilir.

Anahtar Kelimeler: Sürdürülebilirlik, Sürdürülebilir Liderlik, Kurum Kültürü, Örgüt Kültürü. 


\title{
Sustainable Leadership in Maintaining Corporate Culture
}

*

\begin{abstract}
The roles of school principals limited to applying bureaucratic rules in the past have altered in the $21^{\text {st }}$ century. One of these roles is to lead reforms in schools and to ensure that the reforms are sustainable and effective. To fulfill new roles, it may be beneficial for school principals to perform sustainable leadership behaviors that will enable them to turn schools into professional learning communities. A sustainable leadership approach can ensure a reformist, innovative and learning-oriented corporate culture. The study aimed to get teachers' opinions about the importance of sustainable leadership practices to maintain an effective corporate culture. A case study was created by the researchers based on relevant literature. Content analysis was used to determine the presence of codes, categories, and themes. The result of the study exhibited that teachers had a positive attitude towards sustainable corporate culture, they drew attention to managerial sustainability, and they believed that maintaining the corporate culture depended on decisions made by a single person. Sustainable leadership behaviors were exhibited at a limited level by school principals to the participant teachers' opinions. It might be beneficial to conduct longitudinal studies to evaluate whether the effects of sustainable leadership on educational institutions are concrete and long-term.
\end{abstract}

Key Words: Sustainability, Sustainable Leadership, Corporate Culture, Organizational Culture. 


\section{Giriş}

Ekonomik ve kültürel küreselleşme nedeniyle değişen dünyaya uyum sağlamak ve hayatta kalmak için, eğitim kurumları gelişmek ve değişmek zorundadır. Geçmişte rolleri bürokratik kuralları uygulamakla sınır olan okul müdürlerinin sorumluluk alanları, 21. yüzyılda farklılaşmaktadır. (Balyer, 2012). Yeni rollerini yerine getirebilmeleri için, okul müdürlerinin okulları yenilikçi profesyonel öğrenme topluluklarına dönüştürmelerine faydalı olacak sürdürülebilir liderlik tarzını benimsemeleri faydalı olabilir (Hargreaves ve Fink, 2006).

Sürdürülebilir liderlik yaklaşımı, okulların değişen koşullara hızla uyum sağlayabilmeleri için öncelikler belirlemelerine ve uzun süreli eylem planlamaları yapmalarına yardımcı olmaktadır (Gummerson, 2015). Sürdürülebilir liderlik, okuldaki her öğrencinin kendi öğrenme serüveninde başarılı olacağı inancı üzerine kuruludur ve bu anlayışta başarı her öğrenci için erişilebilirdir (Davies, 2007). Sürdürülebilir liderlik anlayışı, okulda reformist ve yenilikçi bir kurum kültürünün oluşturulmasına ve değişen şartlara ve baskı unsurlarına karşı gelişim ve öğrenme odaklı kurum kültürünün kalıcı olmasını sağlayabilir. Mevcut araştırmada, sürdürülebilir liderlik yaklaşımının kurum kültürünün devam ettirilmesine ilişkin öğretmen görüşlerine ulaşılması amaçlanmıştır.

\section{Sürdürülebilir Liderlik}

Sürdürülebilirlik, kısa vadeli ve "miyop" planlamalara bir alternatif olarak; sürdürülebilir faaliyetlerin gelişimini teşvik etmek ve statükoyu dönüştürmek için bilinçli bir çabalama olarak tanımlanabilir (Britannica, t.y.). Ekolojik/çevresel, sosyal ve ekonomik açılardan tanımlanabilen sürdürülebilirlik, kaynakların verimli kullanabilmesini ve sürdürülebilirliğini amaçlayan etik biçimi ve hesap verebilirlik sistemidir (İrge ve Özkan, 2019).

21. yüzyılda sosyal, kültürel, ekonomik ve çevresel açıdan hızlı gelişmeler ve problemler yaşanmaktadır. Küreselleşmenin etkisiyle belirsizleşen dünyada geleceği öngörmek ve şekillendirmek önem kazanmıştır. Dönemsel ve toplumsal şartlar, o çağın liderlerini 
yaratmaktadır. Bu nedenle uzun vadeli sürdürülebilirliği öncelik haline getiren yeni bir liderlik türüne ihtiyaç duyulmaktadır (De Haan, Jansen ve Ligthart, 2015). Sürdürülebilir liderlik, değişen şartlara uygun olarak değişim ve gelişim gösteren, kaynakların verimli kullanıldığı ve boşa giderilmediği bir liderlik anlayışıdır (Soukainen ve Fonsen, 2017). Başka bir deyişle, sürdürülebilir liderlik, kaynakları gereksiz yere tüketmemeyi ve topluma zarar vermemeyi amaçlayan kolektif bir sorumluluğu ifade etmektedir. Sürdürülebilir liderler, paydaşların düşüncelerini önemseyerek, örgütlerde çeşitlilikten beslenen bir eğitim ortamının oluşturulmasını planlamaktadır (Hargreaves ve Dean 2003). Bu liderlik anlayışında sürdürülebilirlik değişim odaklıdır, ancak değişim için geçmiş göz ardı edilmez; kültürel gelenekler, yerel bilgiler ve kolektif hafıza güçlü bir öğrenme ve gelişme kaynağı olarak değerlendirildiği için geçmiş gelecek planlamalarında önemsenmektedir (Hargreaves, 2007).

Eğitimde sürdürülebilir liderlik, okul liderlerinin bütüncül ve kurumlarının ötesinde düşünmelerine yardımcı olmakta ve üyeleri gelişim ve yeniliğe teşvik ederek okulların değişen koşullara hızla uyum sağlamalarını kolaylaştırmaktadır (Gummerson, 2014). Okullarda sürdürülebilir ve etkili reformlar geliştirmenin, eğitim liderleri tarafından zor, hatta imkansız olarak değerlendirildiği ifade edilmektedir (McAdams, 1997). 21. yüzyılda belirsizleşen dünyada, eğitim reformlarının geleneksel yöntemlerden farklı bir anlayışla ele alınması gerekmektedir. Sürdürülebilir liderlik yaklaşımı, liderlerin istikrarlı ve öngörülebilir sonuçlar elde etmeleri için gerçekçi hedefler oluşturmalarına katkı sağlamaktadır; bu nedenle bu liderlik anlayışında etkili reformların geliştirilmesi imkansız görülmemektedir (Gummerson, 2014). Sürdürülebilir liderlik, okulun uzun vadeli başarısının sağlanması ve gelişiminin teşvik edilmesini sağlamaktadır (Hargreaves ve Fink, 2004).

Sınavlar sonucunda yüksek skorlar elde edilmesi sık sık eğitimde bir başarı göstergesi olarak değerlendirilse de sürdürülebilir eğitim liderliğinde, yüksek skorlar her zaman kalıcı bir öğrenme ve iyileşmenin göstergesi değildir (Hargreaves ve Fink, 2003); sürdürülebilir liderlik, öğrenmeyi geliştirmek için geçici kazanımların ötesine geçmeyi hedeflemektedir (Glickman, 2002; akt. Cook, 2014). Bu nedenle, bu liderlik anlayışında, her öğrencinin kendi öğrenme sürecinde, farklı alanlarda 
başarılı olabileceğine inanılmaktadır (Davies, 2015). Başka bir ifadeyle, sürdürülebilir liderlik yaklaşımında başarı hem sürdürülebilir hem de her öğrenci için erişilebilirdir.

Şekil 1'de yer aldığı üzere, eğitimde sürdürülebilir liderlik ile ilgili literatürde üç farklı paradigma yer almaktadır:

"Eight Elements

of Sustainability"

- Fullan (2005)
"Seven Principles

of Sustainability"

- Hargreaves ve Fink (2008)
"Nine Key Factors"

- Davies (2009)

\section{Şekil 1. Sürdürülebilir Okul Liderliği Paradigmaları}

Sürdürülebilir liderlik üzerinde çalışmalar yürüten Gummerson (2015), üç paradigmanın ortak ilkelerini belirlemiştir. Öncelikle, sürdürülebilir eğitim liderliği, ahlaki amaç ve uygulamalara dayanmalıdır. Kararlar stratejik olarak alınmalıdır. Liderler, uzun vadeli planlamanın ve karar alma süreçlerinin okul ve okul dışındaki paydaşlar üzerindeki etkisini dikkate almalıdır. Okul yöneticilerin ve öğretmenlerin yanı sıra; öğrenciler ve ebeveynler ile yerel yönetimler arasındaki simbiyotik (ortak yaşama dayalı) ilişkilere önem verilmelidir. Eğitim liderleri kaynakları korumalı ve geliştirmelidir. Son olarak, öğrenciler, öğretmenler ve toplumla birlikte okul liderleri, eğitimin temel ürünü olarak hayat boyu öğrenmeyi teşvik eden okullar oluşturmalıdır (Gummerson, 2015).

\section{Kurum Kültürü}

Kültür kavramı genel olarak, bir grup insan tarafından paylaşılan ortak yaşam görüşünü ifade etmektedir (Ogbonna ve Harris, 2002). Kültür, aynı zamanda birtakım değerlerin davranışa yansıması olarak 
değerlendirilmektedir (Pratomo, 2020). Örgütlerde bireyler örgütsel amaçların yanı sıra, bireysel amaçları, ihtiyaçları ve amaçlarıyla var olurlar. Bu nedenle, örgüt üyeleri basit bir insan topluluğu olarak değil; kendine özgü bir kimliğe sahip bir olgu olarak çerçevelendirilmektedir (Hoy ve Miskel, 2010, s.164). Örgütleri birbirinden ayıran kimlikleri, örgütsel kültür veya kurum kültürü olarak adlandırılır. Bu araştırmada iki ifade eş anlamlı olarak kullanılacaktır.

Kültür kavramı önceleri yönetim alanında metafor olarak kullanılırken, 1950'l1 yıllardan sonra, yönetsel etkinlik veya kontrol sağlama aracı olarak kullanılmaya başlanmıştır (Bastedo, 2012). Geçmişte örgütsel kültür, "tutum ve eski alışkanlıklar" olarak tanımlanırken, son zamanlarda, "bağlılık ve özveri üzerine kurulu bir ürün" olarak değerlendirilmektedir (Pratomo, 2020, s.55). Lussier ve Achua (2010, s.370)'ya göre, kültür kurum içinde tutarlı davranılmasını sağlayan normatif bir düzendir. Kurum kültürü tüm üyeler tarafından inanılan ve kabul edilen örgütsel değerler kalıbıdır (Arif, Zainudin ve Abdul Hamid, 2019). Kurumca sahiplenilen değerler sıklıkla geçmişle bağlantılıdır (Schein, 1984). Kültürle ilişkili ögeler, çalışanlara ortak kimlik duygusu kazandırmakta ve davranışları üzerinde etkili olmaktadır (Isensee, Teuteberg, Griese ve Topi, 2020). Bu nedenle, kurum kültürünün çalışanlar tarafından benimsenerek güçlü ve etkili olması, örgütlerin yeniliklere açık olması, sürekli gelişimin teşvik edilmesi ve örgütsel performansın geliştirilmesi açlarından önem taşımaktadır.

Kurum kültürünün yönetilip yönetilemeyeceği ile ilgili alanyazında tartışmalar yer almaktadır. Bazı araştırmacılar (Cameron ve Ettington 1988; Denison 1990; Trice and Beyer 1993; akt. Demir, Ayyildiz Unnu ve Erturk, 2011), kültür olgusunu örgütü etkileyebilecek güçlü bir değişken olarak değerlendirirken, diğerleri ise kurumda yer alan alt kültürlerin, kurum kültürünün yönetilmesini engellediğini; bu nedenle kurum içinde kültürün yönetilme fikrinin gerçekçi olmadığını savunmaktadır (Baumgartner, 2009). Pozitivist paradigmadan bakıldığında, kültürü oluşturan değerler ve ideoloji yönetilebilir; bu nedenle kurum kültürü kontrol edilebilen bir olgudur (Linnenluecke ve Griffiths, 2010). Liderler, yöneticiler ve çalışanlar, ortak kurum kültürünü benimsediklerinde, örgütsel belirsizlikler azalırken, örgütsel performansı artıracak sosyal düzen, süreklilik, kolektif kimlik, bağlılık ve ortak vizyon 
geliştirilmektedir (Cameron ve Quinn, 2006). Örgütlerde kültür güçlü olduğunda, bürokrasiye daha az başvurulurken, karar verme süreçleri gelişmektedir (Sezgin, 2010). Anlaşıldığı üzere, kurum kültürü çalışan tutumlarını ve davranışlarını anlamak, örgütsel etkililiği sürdürmek ve iyileştirmek için önem taşımaktadır (Chidambaranathan ve Regha, 2016).

Ĕ̆itim Örgütlerinde Kurum Kültürü: Eğitim örgütlerinde kurum kültürü; planlama, geliştirme ve değerlendirme aşamalarının başarısında etkili bir olgudur (Taslimi, Farastkhah ve Hassanmoradi, 2018). Birçok araştırmacıya göre, etkili okul kültürünün oluşturulmaması, okul gelişimini engellemektedir (Wegner ve Hall, 1998). Her okulun kendi kurum kültürünü geliştirip okuldaki uygulamaları kültürel ögelere uygun olarak tanımlaması önem taşımaktadır (Barkley, 2013). Eğitim kalitesinin sürdürülebilirliğinin sağlamasında, örgütsel kültür ögeleri rol oynamaktadır (Pratomo, 2020).

Bilgiye dayalı örgütlerde fiziksel özellikler değil; işbirliği, meslektaş ilişkisi gibi örgütsel kültür ögelerinin kurumun etkililiğini etkileyen unsurlar olarak değerlendirildiği görülmektedir (Kaarst-Brown, Nicholson, Von Dran ve Stanton, 2004; Sezgin, 2010). Okul, bilgiye dayalı örgütler arasında yer almaktadır; paydaşların iletişimi ve ilişkisi, bağlılık, sadakat ve takım çalışması okul performansı için son derece değerlidir.

Örgütsel kültürün oluşumu, liderlerden etkilenir ve örgütsel kültür de kurum liderlerinin davranışlarında etkilidir (Demir, Uğurluoğlu ve Ürek 2017). Okul performansını geliştirecek kültür tipinin devam ettirilebilmesinde, çağın hızlı değişimlerine karşı yüksek farkındalığa sahip, değişim ve gelişim odaklı, kaynakların verimli kullanılmasını önemseyen bir liderlik anlayışı olan sürdürülebilir liderlik etkili olabilir (İrge ve Özkan, 2019; Soukainen ve Fonsen, 2017). Paylaşılan inançlar, değerler ve vizyon aracılığıyla, işbirliği ikliminden beslenen bir okul kültürü geliştirmek sürdürülebilir liderliğin temelinde yer almaktadır (Hargreaves ve Dean 2003). Sürdürülebilir eğitim liderliği anlayışında okul müdürü ve paydaşlar, güçlü ve etkili okul kültürünün geliştirilmesi için kendilerini adamaktadır (Owens ve Valesky, 2011, s.55, akt. Cook, 2014). Sürdürülebilir liderlik anlayışı, paydaşların karar verme sürecine katılmasına önem vererek işbirliği odaklı öğrenmenin geliştirilmesine yardımcı olmaktadır (Duignan ve Cannon, 2011). 
Sürdürülebilir liderlik anlayışının yaygın olduğu okullarda, 21. yüzyıl becerileri edinmiş, yetenekli ve geleceğin şartlarına hazır; çevresel, ekonomik ve sosyal açıdan sürdürülebilirliği sağlayacak donanımlı bireyler yetiştirilebilir. Gelişim ve etik değer odaklı sürdürülebilir liderlik anlayışı, reformist ve yenilikçi bir kurum kültürünün oluşturulmasında ve devam ettirilmesinde faydalı olabilir. Yapılan literatür taramasında kurum kültürü ve sürdürülebilir liderlik olgularını beraber inceleyen araştırmalara rastlanmıştır, ancak konu ile ilgili eğitim alanında gerçekleştirilen ampirik araştırmaların sayısının sınırlı olduğu anlaşılmıştır. Mevcut araştırmada, sürdürülebilir liderlik yaklaşımının kurum kültürünün devam ettirilmesine ilişkin öğretmen görüşlerine ulaşılması amaçlanmıştır. Araştırmada şu sorulara yanıt aranmıştır:

- Okullarda kurum kültürünün sürdürülebilirliğini etkileyen faktörler ile ilgili öğretmen görüşleri nasıldır?

- Okullarda sürdürülebilir kurum kültürünün faydaları ile ilgili öğretmen görüşleri nasıldır?

- Okul müdürleri tarafından sergilenen sürdürülebilir liderlik davranışları ile ilgili öğretmen görüşleri nasıldır?

- Okul müdürlerinin sürdürülebilir liderlik davranışları ile ilgili öğretmenlerin önerileri nelerdir?

\section{Yöntem}

\section{Araştırmanın Modeli}

Araştırmada nitel araştırma yöntemlerinden örnek olay çalışması kullanılmıştır. Örnek olay çalışması, gerçek veya yaşanması muhtemel bir olayla ilgili olası çözüm önerilerinin sunulması için detaylandırılmış çeşitli problemlerin sunulduğu hikâye türü olarak tanımlanmaktadır (Kish, 2004). Ayrıca örnek olay, olgu ve içerik arasında sınırların net olmadığı durumlarda kullanılır (Yin, 1984, s.23; akt. Yıldırım ve Şimşek, 2016). Mevcut araştırmada, okul yöneticilerinin, sürdürülebilir liderlik davranışlarının kurum kültürünün devam ettirilmesi ile ilgili analizler öğretmen görüşlerine göre örnek olay yöntemiyle yürütülmüştür. Literatür ayrıntılı bir şekilde taranarak araştırmacılar tarafından örnek olay oluşturulmuştur. 


\section{Çalışma Grubu}

Araştırmanın çalışma grubu, amaçlı örnekleme yöntemiyle belirlenmiştir. Amaçlı örnekleme, katılımcıları seçmek için kriterlerin önceden belirlenmesi ve katılımcılarının bu kriterlere göre seçilmesi anlamına gelmektedir (Padilla-Díaz, 2015). Araştırmada, amaçlı örnekleme türlerinden biri olan ölçüt örnekleme yöntemi kullanılmıştır. Bu araştırmada katılımcı seçmek için ölçüt, kurum kültürüne yeterince maruz kalabilmeleri için öğretmenlerin bulundukları okulda en az bir yıldır görev yapıyor olmasıdır. Ölçüt örnekleme yöntemi, az katılımcıyla yapılan araştırmalarda dahi sonuçların güvenilirliğini artırmaktadır (Emmel,2013). Ölçüt örnekleme yöntemi gereğince, kurumlarında en az 1 yıldır görev yapan 15 öğretmene ulaşılmıştır. Katılımcılarla ile ilgili bilgiler Tablo 1'de yer almaktadır.

Tablo 1. Katılımcılarla ilgili demografik bilgiler

\begin{tabular}{llllc}
\hline & Cinsiyet & Eğitim & Branş & Aynı okulda çalışma süresi \\
\hline K1 & Kadın & Yüksek lisans & İngilizce & 6 yıl \\
K2 & Kadın & Lisans & İngilizce & 7 yıl \\
K3 & Kadın & Yüksek lisans & İngilizce & 2,5 yıl \\
K4 & Kadın & Lisans & Türkçe & 1,5 yll \\
K5 & Erkek & Lisans & Türcçe & 2 yıl \\
K6 & Kadın & Lisans & Türçe & 6 yıl \\
K7 & Erkek & Lisans & Sosyal Bilimler & 1,5 yll \\
K8 & Erkek & Lisans & Türkçe & 2 yıl \\
K9 & Kadın & Yüksek lisans & İngilizce & 3 yıl \\
K10 & Kadın & Lisans & İngilizce & 1 yıl \\
K11 & Kadın & Yüksek Lisans & İngilizce & 2 yıl \\
K12 & Kadın & Lisans & Türk Dili ve Edebiyatı & 5 yıl \\
K13 & Kadın & Lisans & Tarih & 2 yıl \\
K14 & Erkek & Lisans & Matematik & 6 yıl \\
K15 & Kadın & Yüksek Lisans & Türk Dili ve Edebiyatı & 5 yıl \\
\hline
\end{tabular}

Amaçlı örneklem yöntemi kullanılarak seçilen 15 öğretmenle oluşturulan örnek olay üzerinden yarı yapılandırılmış görüşmeler gerçekleştirilmiştir. Öğretmenler, farklı branş grupları temsil edecek şekilde seçilmiştir. Katılımcı öğretmenlerin 4'ü erkek, 11'i ise kadındır. Öğretmenlerin 10'u lisans, 5'i yüksek lisans derecesine sahiptir. Branşları incelendiğinde, katılımcı öğretmenlerin 6'sının İngilizce, 4'nün Türkçe, 2'sinin Türk Dili ve Edebiyatı, 1'inin Sosyal Bilimler, 1'inin Tarih ve 1'inin 
Matematik öğretmeni olduğu görülmektedir. Katılımcı öğretmenlerin aynı okulda çalışma sürelerinin en kısa 1 yıl, en uzun ise 7 yıl olduğu görülmektedir. Öğretmenlerin tamamı devlet okullarında çalışmaktadır.

\section{Verilerin Toplanması}

Literatür ayrıntılı bir şekilde taranarak araştırmacı tarafından örnek olay oluşturulmuştur. Veri toplanması için, oluşturulan örnek olay ile ilgili nitel veri toplama yöntemlerinden yarı yapılandırılmış görüşme tekniği kullanılmıştır. Yapı yapılandırılmış görüşme tekniği, katılımcıların cevaplarına göre alt soruları şekillendirmek için kullanışlıdır ve bu nedenle tercih edilmiştir (Creswell, 2007), böylece, araştırma sonuçlarının güvenirliğinin artırılması hedeflenmiştir. Görüşme formu soruları, ilgili literatür ayrıntılı şekilde taranarak oluşturulmuştur. Öncelikle, pilot bir görüşme yapılarak görüşme formunun niteliğinden emin olunmuştur. Daha sonra, araştırma amaçları ve süreci ile ilgili bilgilendirme içeren gönüllü katılım formu e-mail yoluyla katılımcılara gönderilmiştir. Pandemi şartları nedeniyle, görüşmeler video konferans yoluyla yapılmıştır. Görüşmeler, katılımcıların izniyle ses kaydına alınmış ve kelimesi kelimesine yazı ortamına aktarılıp analize hazır hale getirilmiştir.

\section{Geçerlik ve Güvenilirlik}

Araştırmada güvenirliği ve geçerliliğine yönelik çalışmalar yapılmıştır. Nitel araştırmalarda, geçerliğin ve güvenilirliğinden emin olunması için inandırıcılık, aktarılabilirlik, tutarlılık ve teyit edilebilirliğin sağlanması gereklidir (Lincoln ve Guba, 1985). Bu araştırmada, inandırıcılığın, aktarılabilirliğin, tutarlığın ve teyit edilebilirliğin sağlanması için bazı çalışmalar yapılmıştır.

Araştırma sonuçlarının inandırıcılığın sağlanması için, tüm araştırma basamaklarında, alan uzmanı iki uzmandan destek alınmıştır. Araştırmada aktarılabilirliğin sağlanması için, katılımcıların ifadelerinden doğrudan alıntılar yapılmıştır. Tutarlılığın sağlanması için, araştırmacılar kod analizini ayrı ayrı yapmış, daha sonra kodlar karşılaştırılmış ve uzlaşma sağlandıktan sonra veri analizine son verilmiştir. Araştırmada teyit edilebilirliğin sağlanması için, veri dosyaları muhafaza edilmektedir. 


\section{Verilerin Analizi}

Kod, kategori ve temaların oluşturulması için içerik analizi kullanılmıştır. (Strauss ve Corbin, 1990). İçerik analizinin kullanılması, nitel verilerin sistematik olarak kodlama ve analiz etme tekniği ile kavramsal konularla ilişkilendirilebilen kapsamlı bir nitel araştırmanın yürütülmesini sağlamaktadır (Braun ve Clarke, 2012). Verileri analiz etmek için, deşifre edilen görüşmelerden kodlar oluşturulmuş, aralarında benzerlikler aranarak kodlar kategorilere ayrılmış, son olarak benzer kategoriler birleştirilerek temalara ulaşılmıştır. Temalar ve kodlar iki araştırmacı tarafından uzlaşılana kadar tartışılmış ve veri analizine son şekli verilmiştir.

\section{Bulgular}

Kurum kültürünün devam ettirilmesinde sürdürülebilir liderliğin önemine ilişkin öğretmen görüşlerinin belirlenmesi amacıyla yapılan içerik analizi sonucunda, "Sürdürülebilir kurum kültürü" ve "Sürdürülebilir liderlik davranışları" olmak üzere 2 tema belirlenmiştir. "Sürdürülebilir kurum kültürü" teması altında, (i) öne çıkan sürdürülebilir liderlik türü, (ii) sürdürülebilir kurum kültürünün faydaları ve (iii) kurum kültürünün sürdürülebilirliğini etkileyen faktörler alt temaları ortaya çıkmıştır. "Sürdürülebilir liderlik davranışları" teması altında, (i) okul müdürlerinin sürdürülebilir liderlik davranışları ve (ii) sürdürülebilir liderlik ile ilgili öneriler olmak üzere iki alt tema ortaya çıkmıştır. Şekil 2'de ana tema ve alt temalar sunulmuştur. 

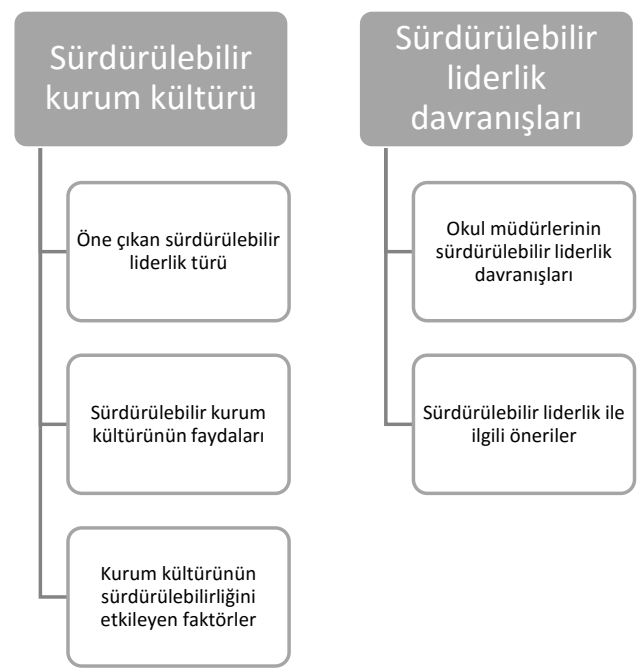

Şekil 2. Kurum kültürünün devam ettirilmesinde sürdürülebilir liderliğin önemine ilişkin öğretmen görüşleri ana teması

\section{Sürdürülebilir Kurum Kültürüne İlişkin Bulgular}

Araştırma bulgularından elde edilen sonuçlar doğrultusunda; sürdürülebilir kurum kültürüne ilişkin öğretmen görüşlerine göre, (i) öne çıkan sürdürülebilir liderlik türü, (ii) sürdürülebilir kurum kültürünün faydaları ve (iii) kurum kültürünün sürdürülebilirliğini etkileyen faktörlere ilişkin görüşler alt temaları ortaya çıkmıştır. İlk alt tema olan öne çıkan sürdürülebilir liderlik türü ile ilgili görüşlere, Tablo 2’de yer verilmiştir.

Tablo 2. Öne çıkan sürdürülebilirlik türü

\begin{tabular}{lll}
\hline Kodlar & f & Tekrar edilme \\
\hline Yönetsel sürdürülebilirlik & & \\
Paydaşlarla sağllklı ve etkili iletişim & 7 & $\mathrm{~K} 2, \mathrm{~K} 4, \mathrm{~K} 6, \mathrm{~K} 10, \mathrm{~K} 12, \mathrm{~K} 13, \mathrm{~K} 15$ \\
Dayanışma ve işbirliği & 3 & $\mathrm{~K} 2, \mathrm{~K} 5, \mathrm{~K} 6$, \\
Ortak karar alma & 2 & $\mathrm{~K} 1, \mathrm{~K} 11$ \\
Destekleyici ve kolaylaştırıcı lider & 2 & $\mathrm{~K} 1, \mathrm{~K} 2$ \\
Farklılıklara değer verme & 1 & $\mathrm{~K} 2$ \\
Motivasyon & 1 & $\mathrm{~K} 10$ \\
\hline Kültürel sürdürülebilirlik & & \\
Kurum aidiyeti & 3 & $\mathrm{~K} 2, \mathrm{~K} 10, \mathrm{~K} 14$ \\
Kurumsal gelenekler & 2 & $\mathrm{~K} 2, \mathrm{~K} 5$ \\
Mezunlarla iletişim & 1 & $\mathrm{~K} 2$
\end{tabular}




\begin{tabular}{lll}
\hline Kodlar & f & Tekrar edilme \\
\hline Ortak değerler ve davranış kalıpları & 1 & K9 \\
\hline Sosyal Sürdürülebilirlik & & \\
Sosyal sorumluluk projeleri & 2 & $\mathrm{~K} 1, \mathrm{~K} 11$ \\
Toplumu geliştirme & 2 & $\mathrm{~K} 1, \mathrm{~K} 9$ \\
Değerlere sahip bireyler yetiştirme & 2 & $\mathrm{~K} 2, \mathrm{~K} 13$ \\
\hline
\end{tabular}

Öğretmenlerin görüşlerine göre, kurum kültürünün sürdürülmesinde en çok yönetsel sürdürülebilirlik öne çıkmaktadır. Yönetsel sürdürülebilirlikte, paydaşlarla sağlıklı ve etkili iletişim ile dayanışma ve işbirliği kodları öne çıkmaktadır. Paydaşlarla olan iletişimin kurum kültürüne olan olumlu etkisini K4 şu şekilde ifade etmiştir:

"Öğrencinin okulu sevmesi ve benimsemesi hususunda birlikte yaprlan çalışmaların büyük katkısı olmaktadır. İletişim oldukça ilişkiler iyi yönde gelişim gösterebilir. Öğretmen ve ebeveyn ilişkisi öğrenci üzerinde olumlu gelişme olacaktır."

K11 ise, ortak karar alma mekanizmanın kurum kültürü için önemli olduğunu şu şekilde ifade etmiştir:

“En sevdiğim şey ortak karar alma mekanizmasının gelişmesi oldu. Müdürün kendi hiyerarşik pozisyonunu kullanmadan temel yap taşının öğretmen olduğunu bilerek onları sürece katması tabii ki hepimizin hayali. Bazıları bunu kısmen başarabiliyor."

Kültürel sürdürülebilirlik, öğretmen görüşlerine göre kurum kültürü açısından önemlidir. K2, mezunlarla iletişim kurum aidiyeti kurumsallaşma ve kurumsal gelenekler ögeleri açısından kurum kültürünün önemini şu şekilde açıklamıştır:

"Hep iletişim halinde olunmast, okulun mezunlar ile hala orada okuyanların iletişim halinde olması herkesin okulla ilgili işlerde işbirliği yapmasını sağhıyor, böyle bir okulun kültüründe kurum aidiyeti de ön plana çıkıyor. Okulun böyle bir çizgisi var, belli bir amacı var, bizim okulda işler bu şekilde yürür diyebiliyorlar yani."

Son olarak, sosyal sürdürülebilirlikte ise, toplumu geliştirme ve sosyal sorumluluk projeleri öne çıkmıştır. K9'un bu konudaki ifadeleri aşağıdaki gibidir:

"Aynı şekilde okuldaki eğitim süreçlerini de yönetiyor okul müdürü. Sadece okul içinde değil dışında da bir bağlantıya sahip mesela o yaptığı projelerle okulun 
çevresine de bir fayda să̆lıyor. Hem iç ögeleri hem de dış mekanizmalarıyla ilişkisi var. Bu kurum kültürü açısından oldukça önemli."

K13 ise, öğrencilere değerler kazandırmak için önemli olduğunu bir anekdotla anlatmıştır:

“Öğrencilerin kendilerini keşfetmeleri için uygun ortamlar okullar tarafindan sağlanmalı. Sanatın, sporun farklı dalların görerek kendini keşfetmeli. Doğa ve hayvan sevgisi için kalplerine bir tohum ekilmeli. Benim 1. sinıf öğretmenim Tema Vakfi'nın rozetini takardı. Bir gün bana da verdi. Yakama taktı. Onu çok sevdiğim için ă̆açlarn da sevmeliyim diye düşünürdüm o zamanlar. Doğa sevgimin ilk tohumunu kesinlikle öğretmenimin attığına eminim. Ona minnettarım."

Öğretmenlerin ikinci alt tema olan sürdürülebilir kurum kültürünün faydalarına ilişkin görüşlerine Tablo 3’te yer verilmiştir.

Tablo 3. Sürdürülebilir kurum kültürünün faydaları

\begin{tabular}{lll}
\hline Kodlar & f & Tekrar edilme \\
\hline Öğretmen motivasyonu & 8 & $\mathrm{~K} 1, \mathrm{~K} 3, \mathrm{~K} 5, \mathrm{~K} 6, \mathrm{~K} 9, \mathrm{~K} 10, \mathrm{~K} 11, \mathrm{~K} 14$ \\
Pozitif okul kültürü & 8 & $\mathrm{~K} 3, \mathrm{~K} 4, \mathrm{~K} 6, \mathrm{~K} 8, \mathrm{~K} 9, \mathrm{~K} 10, \mathrm{~K} 12, \mathrm{~K} 15$ \\
$\begin{array}{l}\text { Aile katılımı } \\
\text { Öğrencilerin sosyal ve ahlaki }\end{array}$ & 5 & $\mathrm{~K} 3, \mathrm{~K} 6, \mathrm{~K} 7, \mathrm{~K} 10, \mathrm{~K} 13$ \\
$\begin{array}{l}\text { gelişimi/duyarlılı̆̆ } \\
\text { Öğrenci motivasyonu }\end{array}$ & 4 & $\mathrm{~K} 1, \mathrm{~K} 2, \mathrm{~K} 7, \mathrm{~K} 10$ \\
$\begin{array}{l}\text { Öğretmenlerin karar süreçlerine } \\
\text { katılması }\end{array}$ & 1 & $\mathrm{~K} 3, \mathrm{~K} 11$ \\
$\begin{array}{l}\text { Gelişime teşvik etme } \\
\text { Öğrencilerin okula aidiyeti }\end{array}$ & 1 & $\mathrm{~K} 1$ \\
\hline
\end{tabular}

Öğretmenlerin hepsi, sürdürülebilir kurum kültürünün kurum ve paydaşlar açısından faydalı olacağını ifade etmiştir. Bu bağlamda, öğretmen motivasyonu öne çıkmıştır. K1, K2 ve K14 bu durumu şöyle ifade etmiştir:

“Öğretmen, teşvik edilmiş hisseder. Projede fikrine önem verildiğini ve değer verildiğini hisseder ve fikrine değer verilen öğretmen, karara katılan öğretmen daha motive olur ve başarnl olmak ve kurumu daha iyi hale getirebilmek için motive ve istekli olur." (K1)

"Maddi manevi herkesin adanması öğrenciler için her öğretmenin isteyeceğ $i$ bir şey. Çeore bilinci, çeşitli projelerin yapılması öğretmenlerin kendilerini geliştirmelerini sağlayacak bir şey." (K2) 
“Öğretmen için her öğrencinin başarılı olabileceği inancının hâkim olduğu bir okul, kendisini her konuda geliştirmesi gerektiği konusunda bir etki sağlayacağı için eğitim öğretime de katkı sağlayacaktır." (K14)

K11 ise, öğretmen motivasyonunun yanı sıra, öğrenci motivasyonunun da olumlu olarak etkileneceğini ifade etmiştir:

"Kafamızdaki projeleri yapmak istiyoruz, ama bütün o fikirler kafamızda kalıyor, uygulamaya geçmiyor. Böyle bir okulda öğretmen işinden kopmayacaktır, elini taşın altına koyacaktır. Aynı şey öğrenci için de geçerlidir, onlar da sadece derslerini görüp okuldan bir an önce gitmek istiyorlar ama süreci ne kadar farklılaştırırsak bu ders başarılarına da etki edecek. Ders başarısı yükselecek çünkü çocuklara farklı bir motivasyon kaynağı sunmuş olacağız."

Öğretmenler aynı zamanda, sürdürülebilir kurum kültürünün pozitif kurum kültürü için önemli olduğunu ifade etmiştir. K3 ve K4, pozitif okul kültürünü ve bu kültürün faydalarını aşağıdaki gibi ifade etmiştir:

“Öğretmenler bunun gibi pozitif bir okul kültürünün bir parçası olmaktan mutluluk duyar ve bu öğretmenin motivasyonunu artırır. Gönüllü olarak yapılan işlerin artmasının yolu açılmış olur. Böyle bir okul kültüründe öğretmenin odağı sadece eğitim-öğretim olacă̆ından mesleki tatmin hisseder." (K3)

"Öğrencinin ve öğretmenin isteklerini önemseyip dikkate alan bir yönetici okul ortamının daha iyi olmasını sağlayacaktır. Öğretmen desteklendiğini bildiğinde düşüncelerini, hedeflerini ve uygulamak istediklerini açık bir şekilde dile getirebilecek, bunun sonunda yararl çalısmalar yapılabilecektir. Bununla birlikte yeni projeler geliştirmekten çekinmeyen öğretmenler, öğrencileri sürece dahil edip öğrencilerin çok yönlü gelişimine katkı sağlayacaklardır." (K4)

$\mathrm{Bu}$ başlığın üçüncü alt teması olan kurum kültürünün sürdürülebilirliğini etkileyen faktörler ile ilgili öğretmen görüşleri Tablo 4'te yer almaktadır:

Tablo 4. Kurum kültürrünün sürdürülebilirliğini etkileyen faktörler ${ }^{1}$

\begin{tabular}{lll}
\hline Kodlar & f & Tekrar edilme \\
\hline Okul müdürünün tutumu & 12 & $\mathrm{~K} 1, \mathrm{~K} 2, \mathrm{~K} 3, \mathrm{~K} 4, \mathrm{~K} 5, \mathrm{~K} 7, \mathrm{~K} 8, \mathrm{~K} 9, \mathrm{~K} 11, \mathrm{~K} 12, \mathrm{~K} 13, \mathrm{~K} 15$ \\
Kurum aidiyeti/Ortak değerler & 6 & $\mathrm{~K} 4, \mathrm{~K} 6, \mathrm{~K} 10, \mathrm{~K} 11, \mathrm{~K} 13, \mathrm{~K} 14$ \\
Okul paydaşlarının rolü & 6 & $\mathrm{~K} 3, \mathrm{~K} 4, \mathrm{~K} 7, \mathrm{~K} 8, \mathrm{~K} 9, \mathrm{~K} 15$ \\
İletişim & 1 & $\mathrm{~K} 4$ \\
\hline
\end{tabular}

${ }^{1}$ Oluşturulan örnek olayda, öğretmenlerin çalıştıkları okul müdürlerinin ayrıldığı ve yeni bir okul müdürünün göreve başladığı ifade edilmiştir. Bu bölümde, öğretmenlerin bu değişim sonucu kurum kültürünün sürdürülebilirliğine ilişkin görüşleri yer almaktadir. 
Kurum kültürünün sürdürülebilirliğini etkileyen faktörlerle ile ilgili öğretmenlerin farklı görüşlere sahip oldukları görülmektedir. Öğretmenlerin çoğu (12/15), kurum kültürünün lider odaklı olduğunu savunmaktadır. K8'in bu konu hakkındaki görüşleri şu şekildedir:

"Yeni müdürün özgür ortamı kısıtlamaya kalkması durumu kötü etkileyebilir. Yeni bir okula atanmıs müdür, kendi kurallarm getirmek isteyebilir, bu da paydaşlar arasındaki söz konusu olumlu tutumun bozulmasına neden olabilir." (K8).

K7 ve K9 ise, kurum kültürünün tek bir kişiye bağlı olduğuna inanmakta, bu durumun sebepleri ise okullardaki bürokratik sisteminin varlığı ile güçlü yöneticilik anlayışı olarak açıklanmaktadır:

"Kuruma atanan idarecilerin nitelikli işlerin ortaya çıkmasında etkili olduğunu düşünüyorum. Sonuçta idarecilerin onayından geçen çok bürokratik bir yaprya hizmet ediyoruz. Bu nedenle, idarecilerin istekli ve teşvik etmesi yeterli olmayabilir."

"Bizim ülkemizde kurumun kültürü doğrudan yöneticiye bağll, bu yüzden okulu bırakın, diğer alanlarda da kurumsalliğa erişmek zor. Yeni okul müdür kendi kurallıyla gelecek, bu durumda kurum kültürü değgişecektir." (K9)

Bazı katılımcı öğretmenlere göre, kurum kültürü okul müdürü gitse bile devam edecektir; çünkü güçlü ortak değerler ve kurum aidiyeti, kurum kültürünün sürdürülmesini sağlayacaktır. K4, K6, K13 ve K14'ün bu konudaki görüşleri aşağıda gibidir:

“Uzun süre içinde bulunulan bir kültürün değişmesinin kolay olduğunu düşünmüyorum. Bu yüzden yönetici değişse dahi gelişmeye, üretmeye ve aktif olmaya alışmış kurumun bu durumu devam ettireceğgini düşünüyorum. İlk sırada öğretmenler etkili olacaktır. Öğrenci istekleri ve öğrenci gelişimi için belirlenen hedefler, kültürün devam ettirilmesini sağlayacaktır." (K4)

"Okul müdürü her şeyden önce öğretmen, ögrrenci ve velilere okula yönelik bir aidiyet duygusunu hissettirmeye çalışmış, bunu içselleştiren öğretmenler bu durumu sonraki dönem öğrenci, veli ve okula yeni katılan öğretmenlere de aktaracaklardır. Böylece süreç içerisinde bu durum devam edecektir." (K6)

"Yeni gelen müdürün eğitim vizyonu önemli de olsa öğretmenlerin, öğrencilerin ve ebeveynlerin dayanışması ile mevcut kurum kültürü korunabilir." (K13)

"Kurum kültürünün devam etmesinde öğretmen, veli ve öğrencilerin ortak değerleri etkili olacaktır." (K14) 
Son olarak, bazı katılımcılar kurum kültürünün devam ettirilmesinin sadece yeni gelen okul müdürünün bağlı olduğunu değil, bu konuda aynı zamanda paydaşların önemli olduğunu ifade etmektedir; K9 ve K15'in bu konudaki ifadeleri aşağıdaki gibidir:

"Bence müdür ayrlldiktan sonra kurum kültürü etkilenir çünkü kurum kültürünü kişiler, eğitim öğretim süreçleri ve dış dinamikler de etkiler ama bence okuldaki kültürün devamını sağlayan en önemli etken kişiler ve en önemlisi okul müdürü. Tabii ki öğretmenlerin motivasyonlarl, ortak bir amaç için çalışması önemli ama bunları sağlayacak olan da okul kültürü, bunun için çabalayacak da okul müdürü." (K9)

"Öğrenci, öğretmen ve velilerin mevcut durumu konusundaki isteklilik ve kararlılıkları çok etkili olacaktır. Yeni gelecek müdürün tutumu da bu konuda olumlu ya da olumsuz etkili olabilir." (K15)

\section{Sürdürülebilir Liderlik Davranışlarına İlişkin Bulgular}

Araştırma bulgularından elde edilen sonuçlar doğrultusunda; sürdürülebilir kurum kültürüne ilişkin öğretmen görüşlerine göre, (i) okul müdürlerinin sürdürülebilir liderlik davranışları ve (ii) sürdürülebilir liderlik ile ilgili öneriler alt temaları ortaya çıkmıştır. İlk alt temaya ilişkin bulgular Tablo 5 'te yer almaktadir.

Tablo 5. Okul müdürlerinin sürdürülebilir liderlik davranışları

\begin{tabular}{lll}
\hline Kodlar & f & Tekrar edilme \\
\hline Öğretmenlere karar süreçlerinde yer verme & 4 & K3, K10, K12, K15 \\
Öğretmeni destekleme & 3 & K10, K13, K14 \\
Teknolojik konularda rehber olma & 1 & K2 \\
\hline
\end{tabular}

İlk alt tema incelendiğinde, katılımcı öğretmen görüşlerine göre, okul müdürlerinin sürdürülebilir liderlik davranışı sergileme düzeyinin sınırlı olduğu görülmektedir. Gözlemlenen sürdürülebilir liderlik davranışları, öğretmenlere karar süreçlerinde yer verme, öğretmeni destekleme, teknolojik konularda rehber olma ve maddi kaynaklar yaratmadır. Çalıştığ1 okuldaki okul müdürünün öğretmenleri karar verme süreçlerinde yer verdiği ile ilgili görüş bildiren K3'ün bu konuda ifadesi aşağıdaki gibidir: 
"Karar alırken bize danışması, hatta bu kararı almadan önce kafamızda böyle bir şey var, siz ne düşünürsünüz demesi çok güzel bir şey, benim okulumda da gerçekleşen bir şey bu."

K10 ise, çalıştığ1 okuldaki okul müdürünün öğretmenlerini desteklediğini şu şekilde ifade etmiştir:

"Ben sosyoekonomik düzeyi düşük bir lisede çalışıyorum ve zaman zaman hem velilerle hem öğrencilerle çatıştığımız oluyor. Böyle anlarda okul müdürümüzün bizi desteklemesi, bir öğretmen olarak bana güven veriyor, işimi daha rahat yapabiliyorum."

Tablo 6. Sürdürülebilir liderlik ile ilgili öneriler

\begin{tabular}{lll}
\hline Kodlar & f & Tekrar edilme \\
\hline Öğretmenle iletişimi güçlendirme & 4 & $\mathrm{~K} 1, \mathrm{~K} 4, \mathrm{~K} 9, \mathrm{~K} 13$ \\
Öğretmeni destekleme/motive etme & 4 & $\mathrm{~K} 5, \mathrm{~K} 6, \mathrm{~K} 9, \mathrm{~K} 12$ \\
Kurum kültürü ve aidiyeti yaratma & 4 & $\mathrm{~K} 2, \mathrm{~K} 9, \mathrm{~K} 10, \mathrm{~K} 14$ \\
Teknoloji konusunda öncülük & 2 & $\mathrm{~K} 1, \mathrm{~K} 11$ \\
Pro-aktiflik & 2 & $\mathrm{~K} 2, \mathrm{~K} 3$ \\
Aile katılımı sağlama & 2 & $\mathrm{~K} 2, \mathrm{~K} 4$ \\
Öğrencinin başarılı olacağına dair inanç & 1 & $\mathrm{~K} 1$ \\
Toplumsal duyarlılık & 1 & $\mathrm{~K} 15$ \\
\hline
\end{tabular}

Tablo 6' da ikinci alt tema olan "sürdürülebilir liderlik ile ilgili öneriler" incelendiğinde, öğretmenlerin okul müdürlerinin sergilemesini beklediği birçok sürdürülebilir liderlik davranışı olduğu görülmektedir. Öğretmenle iletişimi güçlendirme, öğretmeni destekleme/motive etme ve kurum kültürü ve aidiyeti yaratma okul müdürlerinden en çok beklenen sürdürülebilir liderlik davranışları olarak yer almaktadır. K2'nin kurum aidiyetini sağlaması ile ilgili okul müdüründen beklentisini dile getirdiği ifadesi aşağıda yer almaktadır:

"Kurum aidiyeti yaratılması daha çok okul müdürünün elinde, bu durumu o değiştirebilir, böylece biz öğretmenler belki bu şekilde okulu daha iyi bir okula geçmek için hizmet puanı toplamada bir geçiş okulu olarak görmeyi bırakabiliriz."

K9 ise, kurum aidiyeti sağlaması beklentisinin yanı sıra, okul müdürünün öğretmenlerle iletişim noktasında daha becerikli olması gerektiğini ifade etmiştir:

"Bahsedilen örnek okulda arada hiyerarşi yok, rahatça iletişim kurabiliyor, bu da öğretmenin motivasyonunu etkiliyor, eğitim süreci için çok önemli bir şey. Benim okulumda bu yok mesela, biz öyle idarenin yanına rahatça gidemiyoruz, bu bile öğretmenin motivasyonunu etkiliyor. Biz okulun amaçlarını bilemiyoruz 
mesela iletişim yok. Bir de bizde okul kültür oluşturulmaya çok çalışılmıyor, böyle bir çaba yok, örneğin okuldan ayrilan öğretmenlere düzgünce veda edilmiyor veya yeni gelenler düzgünce karşılanmıyor. Ben de ilk geldiğimde bunu yaşadım, idareyle çok kopukluk var."

Son olarak, K2'nin sürdürülebilir liderlik davranışlarından olan proaktifliğe, okul müdürünün sergilemesini beklediği bir davranış olarak dikkat çektiği görülmektedir:

"Pandemi döneminde, uzaktan eğitim sürecinde çok bocaladık. Çünkü öğretmenlerin hiç fikirleri sorulmadan bazı uygulamalar yapıldı, bazı uygulamalardan da kaçınıldı, burada mağdur olan aslında biz öğretmenler ve öğrenciler olduk. Bu bahsedilen okul profili olsaydı bu süreçte bu kadar zorluk yaşamazdık, süreci daha hafif atlatırdık, daha verimli oldurduk."

\section{Tartışma ve Sonuç}

Çalışmada sürdürülebilir liderliğin kurum kültüründeki rolü ile ilgili önemli sonuçlara ulaşılmıştır. Çayak ve Çetin (2018) tarafından yapılan çalışmaya göre, yönetsel, ekonomik, sosyal ve kültürel olmak üzere dört çeşit sürdürülebilirlik liderlik türü vardır. Mevcut çalışmada katılımcı öğretmenlerin görüşlerine göre, kurum kültürünün devam ettirilmesinde en çok yönetsel sürdürülebilirlik liderlik davranışları önemli olarak değerlendirilmektedir; kültürel ve sosyal sürdürülebilir liderlik davranışları yönetsel sürdürülebilirlikten sonra gelmektedir. Mevcut çalışmadaki katılımcı görüşlerine göre, yönetsel sürdürülebilir liderlik türünde; ortak karar alma, dayanışma ve işbirliği, destekleyici ve kolaylaştırıcı liderlik, farklılıklara değer verme, paydaşlarla sağlıklı ve etkili iletişim, motivasyon gibi ögeler kurum kültürünün devam ettirilmesinde öne çıkmaktadır. Ayrıca, mezunlarla iletişim, kurum aidiyeti, ortak değerler ve davranış kalıpları ve kurumsal gelenekler gibi kültürel sürdürülebilir liderlik ögeleri kurum kültürünün devam ettirilmesinde önem taşımaktadır. Bu bulgular, klan tipi örgüt anlayışıyla uyumludur; klan tipi örgütlerde üyelerin bağlılık aracı işbirliği ve sadakattir (Cameron ve Freeman, 1991; akt. Aktan ve Aydıntan, 2016).

Katılımcı öğretmenlerin görüşlerine göre, kurum kültürünün devam ettirilmesinde en önemli faktörün, yönetici olduğu görülmektedir; diğer taraftan okul paydaşları ve kurum aidiyeti de kurum kültürünün devam 
ettirilmesini etkileyen diğer ögelerdir. Demir ve diğerlerine göre (2017), örgütsel kültürün oluşumu, liderlerden etkilenir ve örgütsel kültür de kurum liderlerin davranışları üzerinde etkilidir. Cook (2014) tarafından öğretmenlerin okul müdürlerinin sürdürülebilir liderlik davranışlarını inceleyen araştırmada, sürdürülebilir liderlerin kurum kültürünün devam ettirilmesi için önemli olduğu ifade edilmektedir. Ancak, mevcut araştırmada katılımcı öğretmenlerin çoğunun kurum kültürünün devam ettirilmesini okul müdürüne bağlaması çarpıcı bir sonuçtur. Türkiye'de birçok kurum gibi eğitim kurumlarında paternalist ve geleneksel bir kurum kültürü hakimdir (Collins, 2015); katılımcı öğretmen görüşlerine göre kurum kültürünün sürdürülmesinin tek kişiye bağlı olmasının sebebi, bu geleneksel anlayışın okullarda hakim olmaya devam etmesi olabilir. Kurum kültürünün devam ettirilmesinin faydaları incelendiğinde ise, katılımcı öğretmenlerin çoğunun öğrenci-öğretmen motivasyonu gelişimi, olumlu okul kültürü gibi konularda görüş bildirdikleri görülmektedir. Benzer olarak, alanyazındaki çalışmalarda okul gibi bilgiye dayalı örgütlerde fiziksel özelliklerdense işbirliği, meslektaş ilişkisi gibi örgütsel kültür ögelerinin, kurumsal etkililik üzerinde etkili unsurlar olduğu ifade edilmektedir (Kaarst-Brown, vd., 2004; Sezgin, 2010).

Katılımcı öğretmenlerin görüşlerine göre okul müdürlerinin sürdürülebilir liderlik davranışları incelendiğinde, öğretmenle iletişimi güçlendirme, öğretmeni destekleme ve motive etme, öğrencinin başarılı olacağına dair inanç, teknoloji konusunda öncülük etme, kurum kültürü ve aidiyeti yaratma, pro-aktiflik ve aile katılımı sağlama ögelerinin öne çıktı̆̆1 görülmektedir. Bu sonuçlar, Cook (2014) tarafından yapılan araştırmayla uyuşmaktadır; öğretmenlerin sürdürülebilir okul liderliğini nasıl algıladığına ilişkin çalışmada, katılımcı öğretmenlerin hepsi, mesleki gelişim ve okulun tüm paydaşların karar mekanizmalarına katılması konusunda sürdürülebilir liderlik anlayışını faydalı görmektedir. Bu sonuçlara ek olarak, bazı katılımcı öğretmenlerin okul müdürlerinden uzaktan eğitim sürecinde oluşan kriz ortamını başarıyla yönetmelerini talep etmeleri, sürdürülebilir liderlik anlayışının pro-aktif yapısıyla ilişkili görülebilir (Soukainen ve Fonsen, 2017); başka bir deyişle, öğretmenler okul müdürlerinin beklenmedik gelişmelere hazırlıklı olmalarını ve proaktif olmalarını beklemektedir. Diğer taraftan, öğretmenlerin görüşlerine 
göre, okul müdürleri tarafından sergilenen sürdürülebilir liderlik davranışları oldukça sınırlıdır. Bu sonuç, Çayak ve Çetin (2018) tarafından yürütülen çalışma ile farklılaşmaktadır; çalışmaya göre, öğretmenlerin görüşlerine göre okul müdürlerinin sürdürülebilir liderlik davranışları göstermeleri "Katılıyorum" düzeyindedir; bu farklılığın sebebi, iki araştırmanın farklı metodoloji kullanmaları olabilir. Çayak ve Çetin (2018) tarafından yürütülen çalışmada nicel araştırma yöntemlerinden tarama modeli kullanılırken, mevcut araştırmada nitel araştırma yöntemlerinden örnek olay modeli kullanılmıştır. Ayrıca, bu araştırmanın pandemi şartlarında yürütülmesi, öğretmenlerin okul müdürüyle ilgili beklentilerini farklılaştırmış olabilir. Araştırma pandemi şartları gereği, video konferans yoluyla yürütülmüştür. Bu durum, araştırmanın sinırlılığı olarak değerlendirilebilir.

Çalışmadan elde edilen sonuçlar doğrultusunda araştırmacılara ve politika yapıcılara şu önerilerde bulunulabilir:

- Çalışmada, öğretmenlerin sürdürülebilir liderlik davranışlarını hem kendi kariyer gelişimleri hem de öğrenci başarısı için faydalı olarak değerlendirdikleri sonucuna ulaşılmıştır. Konuyla ilgili boylamsal araştırmaların yapılması, sürdürülebilir liderliğin eğitim kurumlarına olan etkilerinin somut ve uzun süreli olup olmadığının bilimsel olarak değerlendirilmesi açısından önerilebilir.

- Çalışmada katılımcı öğretmenler tarafından kurum kültürünün devam ettirilmesinin tek kişiye bağlı olduğunun ifade edilmesi, dikkat çekici bir bulgudur. Okulların sürdürülebilir başarıya ulaşabilmeleri için, kurum kültürünün oluşturulmasına rehberlik edecek araştırmaların yürütülmesi faydalı olabilir.

- Çalışmada, öğretmenlerin görüşlerine göre okul müdürleri tarafından sergilenen sürdürülebilir liderlik davranışlarının sınırlı olduğu görülmüştür. Gelecek araştırmalarda bu bulgunun sebebi araştırabilir; aynı konuda tekrar çalışma yapılıp bu sonucun sebebinin pandemi şartları olup olmadığı değerlendirilebilir. 


\title{
EXTENDED ABSTRACT
}

\section{Sustainable Leadership in Maintaining Corporate Culture}

\author{
* \\ Münevver Çetin - Şeyda Baş \\ Marmara University
}

Purpose and Significance: The roles of school principals limited to applying bureaucratic rules in the past have altered in the $21^{\text {st }}$ century. One of their new roles is to lead reforms in schools and to ensure that the reforms are sustainable and effective. To fulfill new roles, it may be beneficial for school principals to perform sustainable leadership behaviors that will enable them to turn schools into professional learning communities. A sustainable leadership approach can ensure a reformist, innovative and learning-oriented corporate culture. The study aimed to get teachers' opinions about the importance of sustainable leadership practices to maintain an effective corporate culture.

Methods: A case study was created by the researchers based on relevant literature. A case study research design is used when the boundaries between phenomenon and context are not clearly evident (Yin, 1984, p.23; cited in Yıldırım \& Şimşek, 2016). Content analysis was used to determine the presence of codes, categories, and themes. The use of content analysis enables comprehensive qualitative research that can be associated with conceptual issues by systematically coding and analyzing qualitative data (Braun \& Clarke, 2012).

Results, Discussion and Conclusion: Based on content analysis, 2 themes were determined as "Sustainable corporate culture" and "Sustainable leadership behaviors". Under the first theme, three sub-themes emerged: (i) prominent type of sustainable leadership, (ii) benefits of sustainable corporate culture and (iii) factors affecting the sustainability of corporate culture were determined.

Firstly, managerial sustainability becomes prominent in maintaining the corporate culture according to participants (7/15). In managerial sustainability, the codes "effective communication with stakeholders" and 
"solidarity and cooperation" were emphasized by the participants. Moreover, some participants highlighted importance of cultural sustainability (3/15) and social sustainability (2/15).

Secondly, sustainable corporate culture was considered highly beneficial for the institution and its stakeholders according to all the participants. Taking into benefits of sustainable corporate culture into consideration, especially teacher motivation (8/15) and student motivation (2/15) were expected to be positively affected. Furthermore, teachers stated that sustainable corporate culture is important for positive corporate culture (8/15). Similarly, studies in the literature state that organizational culture elements such as cooperation and colleague relations, rather than physical characteristics of the institution, are effective factors on institutional effectiveness in knowledge-based organizations such as schools (KaarstBrown, et al., 2004; Sezgin, 2010).

Thirdly, participants had different opinions about the factors affecting the sustainability of corporate culture. Most of the teachers (12/15) argued that the corporate culture is leader oriented. According to Demir et al. (2017), the formation of organizational culture is influenced by leaders, and organizational culture is also effective on the behavior of leaders. The study by Cook (2014) which examines the sustainable leadership behaviors of teachers' school principals stated that sustainable leaders are highly important for sustaining the corporate culture. However, it is a striking result that most of the participant teachers in the present study attribute the maintenance of corporate culture to the school principal. In Turkey, like many institutions, a paternalistic and traditional corporate culture is still dominant in educational institutions (Collins, 2015). The reason for which the maintenance of the institutional culture is thought to depend on one person may be derived from traditional understanding dominant in schools. Another possible explanation may be the presence of a bureaucratic system in schools. A few participants highlighted significance of common values (6/15) and role of school stakeholders $(6 / 15)$ to sustain corporate culture. 
Under the second theme, two sub-themes emerged: (i) sustainable leadership behaviors exhibited by school principals and (ii) suggestions for sustainable leadership.

Firstly, sustainable leadership behaviors exhibited by school principals were quite limited according to the participants. This finding differs with the study conducted by Çayak and Çetin (2018) which stated that school principals' sustainable leadership behaviors are at the level of "I agree". The reason for this difference may be derived from different research methods. The quantitative research method was used in the study conducted by Çayak and Çetin (2018), while the qualitative research method was used in the present study. Furthermore, conducting this research under pandemic conditions may have differentiated teachers' expectations about the school principal.

The sustainable leadership behaviors of school principals observed by participants were as follows: Teacher participation in the decision-making process, supporting teachers, guiding them in technological matters and creating financial resources. These results are compatible with the study by Cook (2014) examining how teachers perceive sustainable school leadership. In the related study, all of the participant teachers considered sustainable school leadership behaviors useful for professional development and the participation of all stakeholders in the decisionmaking mechanisms of the school. Secondly, there were a number of sustainable leadership behaviors that teachers would expect school principals to exhibit. Enhancing communication and strengthening teacher-principal relationship, supporting and motivating the teacher, and creating corporate culture and a sense of belonging were the most expected sustainable leadership behaviors.

Limitations: The participants were interviewed via video conference due to the pandemy, which can be considered as a limitation of the research.

Recommendations for future research: It might be beneficial to conduct longitudinal studies to evaluate whether the effects of sustainable leadership on educational institutions are long-term. Lastly, the research topic may be re-studied, and the results may be compared to evaluate whether pandemic conditions have an impact on expectations of teachers. 


\section{Kaynakça/References}

Aktan, E. ve Aydıntan, B. (2016). Cameron-Freeman örgüt kültürü türleri ekseninde örgüt kültürü ve bilgi güvenliği algısı ilişkisi: Devlet üniversitelerinde bir uygulama. İşletme Araştırmaları Dergisi, 8(4), 324344.

Arif, S., Zainudin, H. K. ve Hamid, A. (2019). Influence of leadership, organizational culture, work motivation, and job satisfaction of performance principles of senior high school in medan city. Budapest International Research and Critics Institute-Journal, 2 (4), 239-254. http://dx.doi.org/10.33258/birci. v2i4.619

Balyer, A. (2012). Çağdaş okul müdürlerinin değişen rolleri. Ahi Evran Üniversitesi Kırşehir Eğitim Fakültesi Dergisi, 13(2), 75-93.

Barkley, B. P. (2013). Teacher perception of school culture and school climate in the "leader in me" schools and non- "leader in me" schools. (Doktora tezi). The University of Southern Mississippi, Educational Administration and Supervision Commons, and the Educational Leadership, Mississippi.

Bastedo, M. N. (Ed.). (2012). The organization of higher education: Managing colleges for a new era. JHU Press: Baltimore.

Baumgartner, R. J. (2009). Organizational culture and leadership: Preconditions for the development of a sustainable corporation. Sustainable development, 17(2), 102-113.

Bertels, S., Papania, L. ve Papania, D. (2010). Embedding sustainability in organizational culture. A systematic review of the body of knowledge. London, Canada: Network for Business Sustainability.

Braun, V. ve Clarke, V. (2012). Thematic analysis. In H. Cooper, P. M. Camic, D. L. Long, A. T. Panter, D. Rindskopf ve K. J. Sher (Der.), APA handbooks in psychology®. APA handbook of research methods in psychology, Research designs: Quantitative, qualitative, neuropsychological, and biological (s.5771). American Psychological Association. http://dx.doi.org/10.1037/13620-004

Britannica (t. y.). "sustainability". 10 Aralık 2020 tarihinde https://www.britannica.com/science/sustainability adresinden erişildi.

Cameron, K. S. ve Quinn, R. E. (2011). Diagnosing and changing organizational culture: Based on the competing values framework. San Francisco: John Wiley \& Sons. 
Chidambaranathan, K. ve Regha, V. S. (2016). Diagnosing the organizational culture of higher education libraries in the united arab emirates using the competing values framework. LIBRES: Library ve Information Science Research Electronic Journal, 26(2), 99-112.

Collins, I. (2015). Using international accreditation in higher education to effect changes in organisational culture: A case study from a Turkish University. Journal of Research in International Education, 14(2), 141-154. http://dx.doi.org/10.1177/1475240915592589

Cook, J. W. (2014). Sustainable school leadership: The teachers' perspective. International Journal of Educational Leadership Preparation, 9(1), 1.

Creswell, J. W. ve Poth, C. N. (2007). Qualitative inquiry and research design: Choosing among five approaches. California: Sage Publications.

Çayak, S. ve Çetin, M. (2018). Sürdürülebilir liderlik ölçeği: Geçerlik ve güvenirlik çalışması. Electronic Turkish Studies, 13(11), 1561-1582. http://dx.doi.org/10.7827/TurkishStudies.13703

Davies, B. (2007). Developing sustainable leadership. British Educational Leadership, Management and Administration Society, 21(3), 4-9. http://dx.doi.org/10.1177/0892020607079984

De Haan, T., Jansen, P. ve Lighart, P. (2015). Sustainable Leadership: Talent requirement for sustainable enterprises. Reynolds Associates. 15 Aralık 2020 tarihinde https://www.russellreynolds.com/insights/thoughtleadership/sustainable-195leadership-talent-requirements-forsustainable-enterprises adresinden erişildi.

Demir, C., Ayyildiz Unnu, N. A. ve Erturk, E. (2011). Diagnosing the organizational culture of a Turkish pharmaceutical company based on the competing values framework. Journal of business economics and management, 12(1), 197-217.

Demir, İ. D., Uğurluoğlu, Ö. ve Ürek, D. (2017). The relationship between leadership and organization culture: A literature review. Journal of Strategic Research in Social Science, 3(2), 175-196.

Duignan, P. A. ve Cannon, H. (2011). The power of many: Building sustainable collective leadership in schools. ACER Press: Camberwell, VIC.

Emmel, N. (2013). Purposeful Sampling. Sampling and choosing cases in qualitative research: A realist approach içinde (s.33-45). California: Sage Publishing. 
Eyal, O. ve Roth, G. (2011). Principals' leadership and teachers' motivation. Journal of Educational Administration, 49(3), 256-275. http://dx.doi.org/10.1108/09578231111129055

Fitria, H. (2018). The influence of organizational culture and trust through the teacher performance in the private secondary school. Palembang. International Journal of Scientific ve Technology Research, 7(7), 82-86.

Fullan, M. (2005). Leadership ve sustainability: System thinkers in action. California: Corwin Press.

Gummerson, W. M. (2015). Augmenting sustainable leadership practices with complexity theory. Literacy Information and Computer Education Journal, 6(1), 1247-1255.

Hargreaves, A. (2007). Sustainable Leadership and Development in Education: Creating the future, conserving the past. European Journal of Education, 42(2), 223-233. http://dx.doi.org/10.1111/j.1465-

Hargreaves, A. ve Fink, D. (2003). Sustaining leadership. Phi delta kappan, 84(9), 693-700.

Hargreaves, A. ve Fink, D. (2004). The seven principles of sustainable leadership. Educational leadership, 61(7), 8-13.

Hargreaves, A. ve Fink, D. (2006). Redistributed leadership for sustainable professional learning communities. Journal of School Leadership, 16(5), 550-565.

Hoy, W. K. ve Miskel C. K. (2010). Okulların dış çevreleri. Eğitim yönetimi: Teori, araştırma ve uygulama içinde (S. Turan, Çev.). (7. Baskı). Ankara: Nobel Yayıncillk. (Orijinal eserin yayın tarihi 2005).

İrge, N. T. ve Özkan, A. (2019). Kurum kültürü ve sürdürülebilir liderlik ilişkisine yönelik bir araştırma. Sürdürülebilir Kalkınma ve Yönetim Seтроzуити. 5 Aralı 2020 tarihinde https://surdurulebiliryonetimvekalkinma.aydin.edu.tr/wpcontent/uploads/2019/05/N.T\%C3\%BClin-\%C4\%B0rgeAy\%C5\%9Feg\%C3\%BCl-\%C3\%96zkan-Sempozyum-Bildiri-TamMetin.pdf adresinden erişildi.

Isensee, C., Teuteberg, F., Griese, K. M. ve Topi, C. (2020). The relationship between organizational culture, sustainability, and digitalization in SMEs: A systematic review. Journal of Cleaner Production, 275, 122944. doi: http://dx.doi.org/10.1016/j.jclepro.2020.122944. 
Kaarst-Brown, M., Nicholson, S., Von Dran, G. ve Stanton, J. (2004). Organizational cultures of libraries as a strategic resource. Library Trends, 53(1), 33-53.

Kish, M. H. Z. (2004). Using vignettes to develop higher order thinking and academic achievement in adult learners in an online environment. (Doktora tezi). Duquesne University, Duquesne Scholarship Collection Electronic Theses and Dissertations, Pittsburgh.

Linnenluecke, M. K. ve Griffiths, A. (2010). Corporate sustainability and organizational culture. Journal of world business, 45(4), 357-366. http://dx.doi.org/10.1016/j.jwb.2009.08.006

Lussier, R. N. ve Achua, C. F. (2010). Leadership of culture, ethics and diversity: Culture creation and sustainability. Leadership: Theory, Application ve Skill Development içinde (s.368-387) (4. bask1). South-Western Cengage Learning: Kanada.

McAdams, R. P. (1997). A systems approach to school reform. Phi Delta Kappan, 79(2), 138.

Ogbonna E. ve Harris L. C. (2002). Managing organisational culture: Insights from the hospitality industry, Human Resource Management Journal, 12(1), 33-53. http://dx.doi.org/10.1111/j.1748-8583.2002.tb00056.x

Padilla-Díaz, M. (2015). Phenomenology in educational qualitative research: Philosophy as science or philosophical science? International Journal of Educational Excellence, $1(2)$, 101-110. http://dx.doi.org/0.18562/IJEE.2015.0009

Pratomo, H. W. (2020). The effect of organizational culture and school climate on the quality of education services and their implications on the quality of the graduates. Budapest International Research and Critics in Linguistics and Education, 1, 54-60. http://dx.doi.org/10.33258/birle.v3i1.752

Schein, E. H. (1984). Coming to a new awareness of organizational culture. Sloan Management Review, 25(2), 3-16.

Sezgin, F. (2010). Öğretmenlerin örgütsel bağlılığının bir yordayıcısı olarak okul kültürü. Ĕ̆itim ve Bilim, 35(156), 142-159.

Smart, J. C. ve St. John, E. P. (1996). Organizational culture and effectiveness in higher education: A test of the "culture type" and "strong culture" hypotheses. Educational Evaluation and Policy Analysis, 18(3), 219-241. http://dx.doi.org/10.3102/01623737018003219. 
Soukainen, U. ve Fonsén, E. (2018). Will the leadership last? Sustainable leadership in early childhood education. E. Rogulj, A. Jevtić, \& A. Jurčević - Lozančić (Der.), Early Childhood Realtionships: The Foundation for a Sustainable Future: Proceedings, International Scientific and Professional Conference OMEP 2017 içinde (s.312-329). OMEP Hrvatska.

Strauss, A.L. ve Corbin, J.M. (1990). Basics of qualitative research: grounded theory procedures and techniques. New York: Sage Publications

Taslimi, M., Farastkhah, M. ve Hassanmoradi, N. (2018). Factors, Shaping Fields and Typology of Organizational Culture of School on Tehran City. Journal of Education and Practice, 9(8), 62-72.

Wegner, C. ve Hall, O. (1998). Improving schools through the administration and analysis of school culture audits. Mid-South Educational Research Association. New Orleans, LA. 1 Aralı 2020 tarihinde https://eric.ed.gov/?id=ED458299 adresinden erişildi.

Yıldırım, A. ve Şimsek, H. (2006). Sosyal bilimlerde nitel araştırma yöntemleri (10. baskı). Ankara: Şeçkin Yayınclık.

\section{Kaynakça Bilgisi / Citation Information}

Çetin, M. ve Baş, Ş. (2021). Kurum kültürünün devam ettirilmesinde sürdürülebilir liderlik. OPUS- Uluslararası Toplum Araştırmaları Dergisi, 18(44), 8232-8260. DOI: 10.26466/opus.910771. 